\title{
A comparative analysis of the South African and Global Tourism Competitiveness models with the aim of enhancing a sustainable model for South Africa
}

\author{
S. Maharaj, R. Balkaran \\ Durban University of Technology, South Africa \\ *rishi@dut.ac.za
}

\begin{abstract}
The quality of life of society as a whole is to a considerable extent determined by the role of government. South African society is characterised by the presence of a wide gap between the rich and the poor. This is exacerbated by the presence of poverty, HIV/AIDS, crime, corruption and exploitation. Governments attempt to address these contradictions are encapsulated in various policies that detail in accurate form, the needs of the majority of South Africans. Whilst policies depict the needs of the majority of South Africans, these needs remain undelivered. The void between the formulation of policy and service delivery has been most severely felt by the poor. Policy implementation is the responsibility of central, provincial and local government. The policy on tourism has been identified as one of the major players in resolving the impasse that is experienced by government. According to South Africa's National Tourism Sector strategy ( 2011 \& 2016) the country's tourism's economic contribution is set to increase from R318, 16 billion by 2015 to R499 billion by 2020. The challenge however, remains in harnessing Tourism policy in a way that addresses the past and current contradictions. Legislative provisions, policies and plans have set the tone in terms of the direction that tourism should be heading. Public sector institutions at national, provincial and local levels have equipped themselves to develop and enhance the tourism industry in such a way that it resonates with the South African tourism imperatives. This places within context the role of public organisations and its capacity to deliver in terms of government's national imperative. The tourism industry is complex with a range of different stakeholders. There is an inextricable link between the tourism and hospitality industries. This paper attempts to improve on the South African tourism competitiveness with the expressed intention of enhancing growth and sustainability.
\end{abstract}

Keywords: Tourism Competitiveness, destinations, sustainability, economy

\section{Introduction}

According to the National Department of Tourism's growth strategy (2011 \& 2016) South Africa must be a top 20 global destination by the year 2020. The World Economic Forum with various tourism leaders and the travel and tourism industry conducted research of the travel and tourism industry on a global platform. The results of the World Economic Forum for Travel and Tourism Competitiveness Report (WEFTT) 2013 state that the travel and tourism sector in each country play an important role in job creation due to many countries suffering from high unemployment. The Travel and Tourism industry in SA needs to contribute to job creation, quality work, poverty reduction, and global growth, economic growth and sustainability. Therefore South Africa needs to enhance its destination competitiveness, improve economic growth and ensure sustainability of its Travel and Tourism industry.Destinations have become more market orientated therefore the need for strategic marketing at destinations. The competitiveness of a destination must be measured long - term. Factors such as the attractiveness of South Africa must be considered. South Africa needs to consider its natural capital, infrastructure, economy and core attractors. Tourists first decide on destinations and then purchase a holiday. Tourists also have a variety of destinations to choose from therefore South Africa must be a first choice destination.

\section{Literature Review}

As stated by the policy and practice for global tourism by UNWTO (2011: 94) suggests that destination competitiveness is one of the major themes associated with destination development as it affects the profitability and long-term sustainability of destinations. The policy and practice for global tourism by 
UNWTO (2011: 97) states that factors which shape destination competitiveness are investment, productivity, macro-economic policy, branding, image, price, market share, visitor satisfaction, safety, quality of experiences, innovation, strategy and training of human resources. Consistent with the policy and practice for global tourism by UNWTO (2011: 38) states that sustainability is the biggest single issue facing the tourism sector globally. Sustainability affects all aspects of human activity and the planets resources which are expected to support a growing population. The increasing levels of travel and tourism consumptions are accompanied by the rise in the negative impacts of tourism. In line with the World Travel \& Tourism Council's (WTTC's) report on the Travel and Tourism Economic Impact (2013) for South Africa indicates that destinations need to be willing to invest in infrastructure suitable for new sources of demand. In relation to the South Africa's global tourism competitiveness programme industry SA has been benchmarked against Australia, Brazil, Kenya and Thailand. The key focus areas of this policy document are transformation, market access, air access, aviation pricing, public transport, safety and security, information, innovation, product development, investment, skills development and quality assurance and SMME development which are contributing factors to destination competitiveness. With reference to SA's Whitepaper document on Tourism Part V, (May (1996) focuses on Igniting the engine of tourism growth in the country by improving safety, security, investment opportunities environmental and cultural sustainability, product development, transportation, infrastructure, marketing and promotion, product quality and cooperation.

The SA National Tourism Departments Strategic Plan for the years (2014 \& 2015) focuses on the following aspects which Durban Tourism should also adopt in their competitiveness model. The main aspects are as follows: tourism growth, tourism research, sustainable tourism, service excellence, destination competitiveness and grading of accommodation. With reference to the National Department of Tourism's Growth Strategy (2011 \& 2016) which refers to SA as a quality tourism destination that offers world class service with the correct marketing approach that fulfils the expectations of tourists through delivering world class visitor experiences; attracting ongoing investments, the protection of SA's environment and community involvement in tourism. This document also states that a strategic outcome is to improve competitiveness growth and sustainability of the tourism industry. As stated by the National Tourism Sector Strategy (2011) the main strategic objectives are to improve tourism growth and the economy, visitor experiences and SA's brand, sustainability and good governance. According to this research tourism stakeholders need to take into account the global exchange rate volatility, fuel costs, advancement in technology, policy response to climate change, green growth agenda, changing demographics and lifestyles and price conscious consumers. With reference to the National Department of Tourism's Strategic Plan and Annual Performance Plan (2012 \& 2013(4)) which states that SA must be positioned as the world's top 20 tourism destinations by the year 2020. In order for this to be achieved traditional markets need to be sustained, new markets identified, strengthening of regional integration, and identifying new niche markets. This document also states that SA is endowed with natural resources, which if properly used can benefit the country but needs to be preserved and sustained in the process. This plan also introduces the international and domestic tourism plans to grow the contribution of various tourism sectors. Section 6 of this plan states that one of the Organisational Strategic goals is improved levels of competitiveness and sustainability in the tourism industry.

In line with the National tourism development plan which stipulates that visitors to SA need to enjoy their stay and want to return to SA. These areas are growing tourist volumes, expanding tourist length of stay, reducing the pattern of seasonality to all year round visitors, increase in tourist spend; enhance provincial distribution, consumer driven and international destination competitiveness. According to the National Tourism Departments Medium - Term (2010 - 2015) objectives are sustainable tourism growth and development, to ensure competitiveness of the tourism sector and to address imbalanced geographic spread and seasonality of tourists and visitors. The policy document by South African Tourism which focuses on the Marketing Tourism Growth Strategy for South Africa (2011-2013) states that there needs to be focus on retaining current purchasing patterns by existing travellers and segments, stimulating current consumers to visit SA for a longer duration, stimulate current customers to visit for new experiences, offerings and purposes, convert consumers and segments from the competitor to SA, and convert low-frequency or nontravellers into frequent travellers, or short - haul visitor's to long haul visitors. This plan also discusses the growth of event and business travellers on a domestic and international level. The six key objectives are an increase in tourist volume, spend and length of stay, geographic spread, seasonality and promote transformation. The key challenges regarding competitiveness are that SA needs to differentiate itself from its 
competitors in a dynamic world market, re-visit the tourist portfolio markets, delivering to consumers what they want and focus on the upgrade of tourism products and services to deliver against the marketing message.

\section{South Africa's Tourism Competitiveness}

The World Economic Forum engages key industry and thought leaders on a global platform to carry out and in depth analysis of the travel and tourism competitiveness economies across 140 different countries. The purpose of this report is to provide strategic tool for measuring the factors and policies that make it feasible to develop Travel and Tourism in different countries. The results of this report of countries worldwide can enable stakeholders to work together to improve the travel and tourism industry's competitiveness in their national economies. The purpose of this document is to establish how South Africa can enhance its destination competitiveness using the research findings of this research report. Loubser, Martins \& Wyk (2006: 521) state that rapid changes characterize global business activities and global markets. The quantitative and qualitative data secondary data was used from the Global Tourism Competitiveness Report 2013 to determine methods of enhancing SA's Tourism Competitiveness. Loubser, Martins \& Wyk (2006: 99) state that secondary data is defined which can be used in solving the problem under study. According to Bell \& Bryman (2007: 642) mixed method research is research that integrates quantitative and qualitative research. A mixed method research method was used in this research report. With reference to the executive summary in the Travel and Tourism Competitiveness Report 2013 report, South Africa is ranked 3rd in the region of Northern Africa and the Middle East. South Africa is placed at 17th place for its natural resources and 58th for its cultural resources, based on its many World Heritage sites, its rich fauna, its creative industries, and the many international fairs and exhibitions held in the country". SA's transport infrastructure ranked at $43^{\text {rd }}$ position, road quality at $46^{\text {th }}$ position, road quality at $42^{\text {nd }}$ position. SA's policy, rules and regulations ranked at $29^{\text {th }}$ position with tourism continuing to be one of the five priority areas in the countries growth plan. The areas of great concern are SA's safety and security which ranks at $117^{\text {th }}$ position, health and hygiene which ranks at $87^{\text {th }}$ position, this contributes to the concern about access to improves sanitation which also contributes to poor health of much of the workforce which ranks at $129^{\text {th }}$ position, high rate of communicable diseases such as HIV ranking at $137^{\text {th }}$ position. Increase in fuel prices which rank at $77^{\text {th }}$ position and ticket taxes and airport charges ranking at $105^{\text {th }}$ position.

\section{Findings and Recommendations}

South Africa as a destination needs to ensure that tourism sustainability is the focal point for the interconnections between the visitor, the tourism sector and resources when developing policies and plans. The development of a sustainable destination competitiveness model is essential for South Africa UNWTO suggests that tourism is dynamic and it requires differentiation, innovation and renewal on a continuous basis. In relation to the World Economic Forum for Travel and Tourism (2013: 318) competitiveness research report SA's rankings were as follows when compared to the other 139 countries: T\&T regulatory framework $81 / 140$, business environment and infrastructure 59/140, T\&T human, cultural and natural resources $57 / 140$, policy and regulations $29 / 140$, environmental sustainability $52 / 140$, safety and security $117 / 140$, prioritization of travel and tourism 62/140, health and hygiene 87/140, air transport infrastructure 43/140, ground transport infrastructure 43/140, tourism infrastructure, 54/140, ICT infrastructure 81/140, price competitiveness in the T\&T industry 71/140, Human resources $132 / 140$, affinity for travel and tourism 44/140, natural resources 17/140 and cultural resources 58/140.

The findings and comparison of SA's ranking in the World Economic Forum for Travel and Tourism Competitiveness Report 2013 research report indicated in the diagram below which is a clear indication for the government in SA to address national tourism policy in the country thus improving SA's tourism competitiveness. The SA government can ensure that it has more conducive policies regarding travel and tourism which focus on attracting outside investment. Environmental sustainability is crucial to ensuring that a county remains attractive, here a country's environmental regulations are measured. SA needs to have stringent legislation on environmental sustainability by reducing levels of pollution and environmental damage. SA needs to have more safety and security measures in place which needs to become an immediate priority area. Safety and security is a critical factor because tourists are deterred from travelling to dangerous 
countries. Health and hygiene with access to drinking water and sanitation in SA is vital because if tourists become ill then the country's health care system must be able to provide the appropriate care required. SA's government needs to prioritize this sector which impacts on the tourism competitiveness of the country. SA's air transport infrastructure which provides access to and from other countries can improve by developing additional gateways into and out SA, increase its departures and arrivals from operating airlines. The quality of SA's ground infrastructure which includes quality of roads, rail and ports, national transport networks which must offer efficient accessible transportation to key business centres and tourist attractions is essential to SA's Tourism competitiveness.

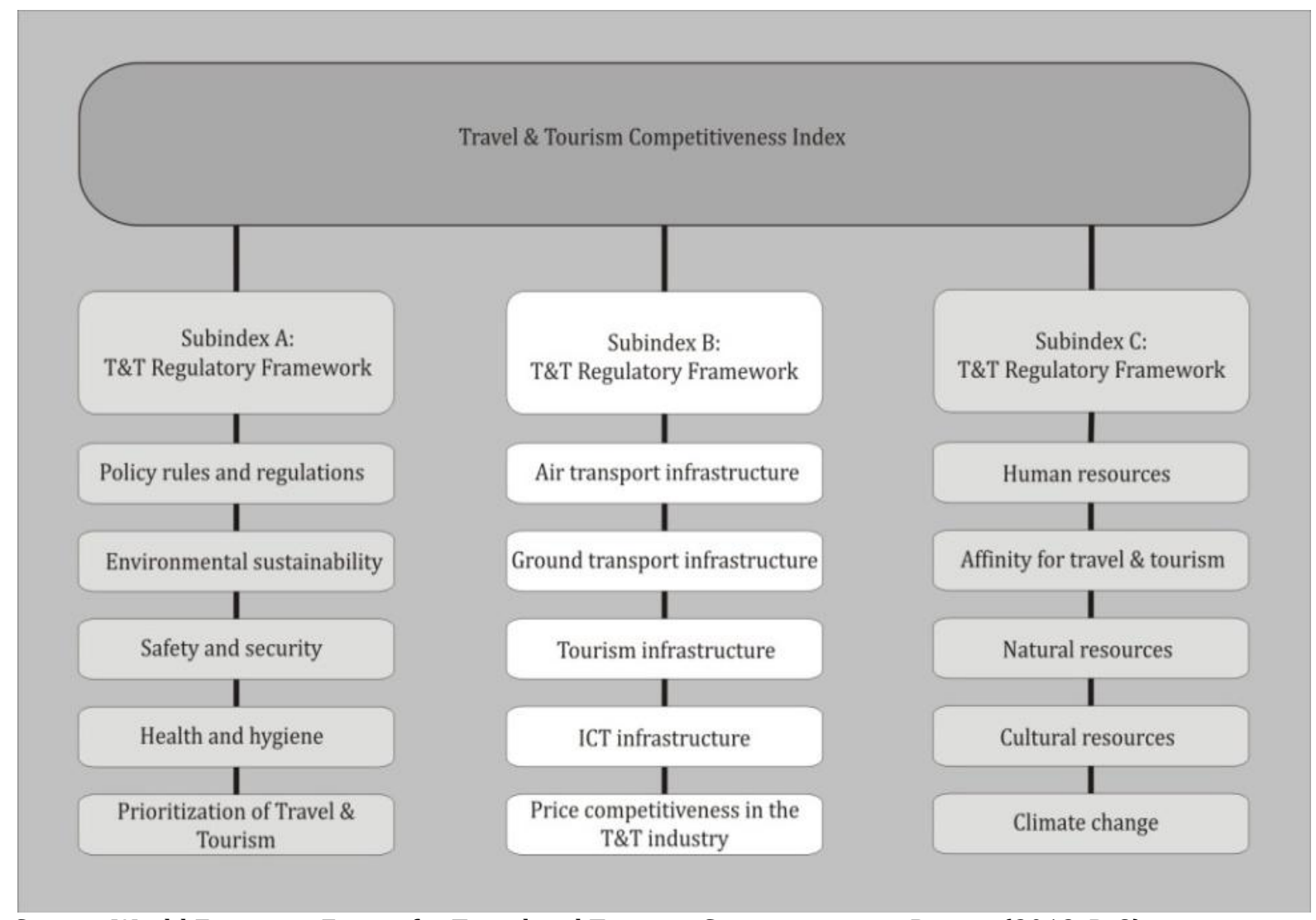

Source: World Economic Forum for Travel and Tourism Competitiveness Report (2013, P, 8)

SA's tourism infrastructure which includes accommodation and other travel services need to offer excellent service to tourists thus improving tourism competitiveness. Infrastructure such as the number of rooms, car rentals and financial infrastructure is available to tourists. SA needs to improve its ICT infrastructure which is becoming more vital for the travel and tourism industry in planning of itineraries and purchasing travel services and accommodation with the use of the internet, telephone lines, mobile phones and broadband. Price competitiveness of the travel and tourism industry in SA is vital because the lower the costs the increased level of competitiveness. The prices of airfare ticket prices, airport charges, fuel prices, and tax and accommodation prices contribute to SA's tourism competitiveness. SA needs to ensure quality human resources which would contribute to service excellence thus ensuring that the tourism industry grows and develops. Customer satisfaction is vital to SA's tourism competitiveness. Sustainability of SA's natural resources is vital to the competitiveness of a county. Countries that offer travellers access to natural assets have a competitive advantage. The cultural resources of a country add to a country's competitiveness. World Heritage sites, sports stadiums seat capacity, the number of national and international exhibitions are vital as attracting factors in SA. Pietsch \& Ringbeck (2013: 43-47), state in their research that cultural resources of a country are significant and enhance a country's competitiveness. SA can enhance its tourism competitiveness by increasing and sustaining its World Heritage sites, sports stadium seat capacity, and the number of 
international fairs and exhibitions in the country, as well as a measure of its creative industries exports, which provides an indication of cultural richness. SA has an advantage of many cultures.

The World Economic Forum for Travel and Tourism Competitiveness Report (2013: 44) suggests that there are shifting trends in international customer origins and profiles. Therefore it is important to analyse existing destination marketing and tourism development planning in the context of the challenges of a more volatile macroeconomic environment in SA. SA tourism policymakers should identify and focus on their country's key competitive advantages over other countries and cities and differentiate the traveller's experience in their country from the experience to be had elsewhere. The shifting trends in international customer origins and profiles. It is important to examine existing destination marketing and tourism development planning in the context of the challenges of a more volatile macroeconomic environment in SA. Despite increasing instability induced by economic, political, and environmental challenges, tourism is expected to remain a significant driver of future economic growth. SA tourism policymakers must concentrate on their countries' most prominent assets and must be able to leverage them effectively to enhance long-term stability. Price competitiveness will continue to influence travel behaviour, this may impact on areas in SA that focus on budget travellers. Tourism stakeholders in SA need to focus on price versus quality. Tourism policy makers in SA need to focus on investment and entrepreneurship and providing unique travel experiences. Tourism policy makers in SA must also focus on sustainability of natural and cultural resources. The new tourists are now demanding green travel offerings instead of traditional sun and beach vacations. Policy makers need to undertake long term tourism master planning. Safety and security is clearly linked to inbound tourism. SA needs to focus on high crime areas and areas with political instability. According to (Delacy, Lipman \& Whitelaw, 2013: 71-76) travel and tourism must play a key role in societal change by engaging in new transport platforms, networks, new climate-proofed hotel design construction, new green models for business meetings, new tactics for community engagement, new visions for education and training. The National Department of Tourism in SA can adopt the 2050 roadmap in the World Economic Forum for Travel and Tourism Competitiveness Report (2013: 74) research to respond to a changing marketplace in uncertain times, engage transform to low carbon, resource-efficient transportation system, assess trends to improve competitiveness and the overall visitor economy, handle increasing number of visitors and control their impacts more sustainably, improve community development with focus on employment, engage local stakeholders and industry employees in transformation.

\section{Conclusion}

South African tourism policy makers and tourism stakeholders can use the World Economic Forum for Travel and Tourism Competitiveness Report 2013 as a tool to benchmark against other countries used in the research to adopt best practice and adapt national tourism policies and the national development plan. The enhancement of South Africa's current tourism competitiveness model would benefit the country and its economy Brent \& Ritchie (2003: 1) states that although the attractiveness of a destination may remain constant, the changing nature of competition need ongoing reassessment of the ability of a destination to compete. In order to develop a competitiveness model for SA as a destination, the cities macro and micro environmental factors need to be analysed and their competitiveness. According to Poon (1993: 291) a destination can enhance its competitiveness by putting the environment first, making tourism a lead sector, strengthening tourism distribution channels in the market place and building a dynamic private sector. SA tourism should also focus on the concept of new tourism rather than mass tourism. There should also be clearly defined market segments in the tourism industry.

\section{Reference}

Brent, J. R. \& Ritchie, J. R. (2003). The Competitive Destination: A sustainable tourism perspective. CAB International.

Bell, E. \& Bryman, A. (2007). Business Research Methods. Oxford University Press.

Delacy, T., Lipman, G. \& Whitelaw, P. (2013). Competiveness, Jobs, and Green Growth: A Global Model. Geneva: WEF Printer

Geneva. (2013). The World Economic Forum Travel and Tourism Competitiveness Report. WEF Printer. 
Martins, J. H., Loubser, M. \& Wyk, H. D. J. V. (1996). Marketing Research a South African Approach. Unisa Press. Pretoria.

Pietsch, T. \& Ringbeck, J. (2013). How to Succeed as a Tourism Destination in a Volatile World. Geneva: WEF Printer.

Poon, A. (1993). Tourism Technology and Competitive Strategies. CAB International.

Republic of South Africa. The National Department of Tourism, 2011-2016. Medium-Term Strategic Plan. Pretoria: Government Printer.

Republic of South Africa. The National Department of Tourism, 2011. National Tourism Sector Strategy. Pretoria: Government Printer.

Republic of South Africa. South African Tourism, 2011-2013. The Marketing Tourism Growth Strategy for South Africa. Pretoria: Government Printer.

World Travel and Tourism Council. (2013). Travel and Tourism Economic Impact 2013 - South Africa. London. WTTC Printer. 